\title{
Emotions, narrative and change
}

\section{Óscar F. Gonçalves \& Paulo P.P. Machado}

To cite this article: Óscar F. Gonçalves \& Paulo P.P. Machado (2000) Emotions, narrative and change, European Journal of Psychotherapy, Counselling \& Health, 3:3, 349-360, DOI: $10.1080 / 13642530010012002$

To link to this article: https://doi.org/10.1080/13642530010012002

曲 Published online: 22 Oct 2010.

Submit your article to this journal

Џll Article views: 144

Q View related articles $\longleftarrow$

4 Citing articles: 4 View citing articles 준 


\title{
Emotions, narrative and change
}

\section{Óscar F. Gonçalves and Paulo P. P. Machado University of Minho, Portugal}

\begin{abstract}
There is a wide agreement that emotions are central to the evaluation and understanding of change processes in psychotherapy. Unfortunately, most of the debate on the role of emotions has been influenced by the reductionist view of 'psychophysiological symbolism' (Averill 1996). We defend the position that, in order to understand their role in psychotherapy fully, we need to move in the direction of a more complex view of emotions. This paper presents a view of emotions as social constructed phenomena operating via language and narrative. We present research suggesting that these narratives may be an essential process for understanding psychological disorders, how these disorders are developed and, finally, how they can be changed.
\end{abstract}

Keywords: emotion, narrative, psychotherapy change processes

\section{Emotions and change in psychotherapy}

Since human knowing is basically tacit, embodied and affective, an understanding of emotional processes seems to be crucial to our understanding of human change processes and psychotherapy (Mahoney 1991). Psychotherapy itself began at the end of last century as a process of releasing repressed emotion (Orlinsky and Howard 1986).

Most psychotherapists would agree that emotional processes are crucial to effective psychotherapeutic process. For example, Mahoney et al. (1989) surveyed 486 American clinical psychologists of different theoretical orientations, including psychoanalytic, behavioural, humanistic/experiential, cognitive and eclectic. More than 80 per cent of the therapists agreed that the optimal psychotherapist would in some way help their clients understand feeling and emotions. 
But, psychotherapy and psychology have not always dedicated their efforts to the scientific understanding of emotional processes. Zajonc (1980), in his provocative article on 'Feeling and thinking', accused academic psychologists of systematically neglecting the study of emotional processes. He urged psychologists to dedicate themselves to the study of human emotion as a phenomenon in itself, and not as an epiphenomenon of cognitive activity. This position initiated a lively debate between those who defended the primacy of emotions versus those who defended the primacy of cognitions in human information processing (cf. Lazarus 1982, 1989; Zajonc 1980).

Although psychotherapy is known as the 'talking cure', an expression sometimes taken as an indication of an exclusive cognitive orientation, some approaches never stop to emphasize the value of motor action and emotional experience. Greenberg and Safran $(1987,1989)$ have repeatedly argued that long-lasting therapeutic change is closely linked with, if not dependent on, activating emotional processes.

From the onset of psychotherapy, almost 100 years ago, there was an appreciation of the role of emotions in human functioning and psychological disturbance. It is always some kind of emotional discomfort that brings patients into psychotherapy. However, the major psychotherapeutic approaches and perspectives hold different views on the role played by emotions in human functioning. For example, in contrast with psychodynamic theory that focuses on the pathogenic nature of repressed affect, behaviour therapy focuses on the clinical effort of modifying undesirable dysfunctional affective states. On the other hand, cognitive approaches see emotional experience, primarily, as a post-cognitive phenomenon, while experiential/humanistic approaches emphasize the adaptive role of emotional processes.

Support for the importance of emotions in the process of therapeutic change can also be found in the literature on therapeutic process. For example, Orlinsky and Howard (1986) concluded that the experience of negative emotion, especially in the first part of the therapeutic process, was related to positive outcomes. Likewise, Hill and O'Grady (1985) showed that therapists rated sessions as best when their intention was focused on intensifying clients' emotional experiences or promoting acceptance of their emotions.

\section{A narrative approach to emotions}

Most of our current thinking on emotions is deeply rooted in a longestablished biological tradition. Therefore it is no surprise that both neurologists and psychophysiology-oriented psychologists are in the forefront of the study of emotions (cf. Damásio 2000). According to biological 
and psychophysiological traditions, the objective is still the one advocated long ago by phrenology - the search for the so-called 'Emotional Centre'. Hopefully this nuclear centre would be responsible for ruling our 'emotional being' and its structural and functional disorders would finally explain the aetiology of emotional suffering. At the end, emotional disorders would be a sub-chapter of the neurological diseases, and psychotherapy would be replaced by pharmacological or even surgery interventions. This is what Averill (1996) has come to define as the 'psychophysiological symbolism' - the idea that emotions as irrational, involuntary and animal processes can be reduced to discrete physiological mechanisms.

Of course, biological structures and physiological processes are fundamental for emotions to occur. However, reducing emotions to the location of biological structures and identification of physiological processes would be equivalent to the ridiculous statement that vision is located in the eye and that the complexities of visual perception are understood by the exploration of all the related physiological mechanisms. As Averill aptly noted, "the eye is necessary for vision, but vision is not "located" in the eye - or in the thalamus, or in the occipital cortex, whose destruction also will produce blindness' (1996: 220). All these biological structures are fundamental for vision to occur but they cannot explain the full complexity, the aesthetic and social nature of visual perception, namely the welldemonstrated phenomena of blind-sight vision or repression, showing that vision is also very emotional (cf. Williams et al. 1997).

The brain and, to a large extent, the person are very complex systems, systems that can be understood only by taking into account both motor action and social nature. First, motor action because the way in which we are acquainted with both internal and external sensations is the product of what Weimer (1997) refers to as 'constructive motor skills'. That is, we are not passive reactors to our sensations - quite the contrary: we proactively construct our own sensory order (Mahoney 1991). Then, social nature because the construction of our emotions is the product of historically and cultural situated interchanges among the members of our social network (Gergen 1994). That is, we construct our emotional order by actively negotiating it with our historical and cultural community. In other words, emotions are motor and social constructions. The central meaning of emotion is movement ( $\mathrm{e}+$ movere), a movement that takes place within the person, but determined by a larger choreography of movement among persons.

But what are the central vehicles for this negotiation to take place?

It is precisely in this negotiation process that language acquires a central place. As social constructionists have repeatedly emphasized, it is by all sorts of language games that human beings not only symbolize but also create, expand and communicate their experiences. It is through language 
that we construct emotions, locating them in a social and cultural context (Lupton 1998).

We now have evidence, from different research areas, that there are certain qualities of experience that are pre-verbal (cf. Greenberg and Safran 1987). These experiences are responsible for an indefinable felt sense that may predispose, although not limiting, the possibilities of emotional construction. The way the person chooses to symbolize the emotion is already a social construction process, in which language is used to create and expand the meaning of the felt sense. By this process, the felt sense becomes a verbally expressed emotion. Thus, language serves three interrelated functions: symbolizing the experience; socializing the experience; and liberating the experience. Symbolizing because it is language that allows the possibility of expressing the meaning of the experience; socializing because this expressed meaning is shaped by cultural and social language interchange; and, finally, liberating because language allows the possibility of creatively multiplying the infinity of emotional meanings out of an initial felt sense. In sum, what we are defending here is the idea that the so-called felt sense is a very illusory phenomenon, very raw material, a departure lounge from which the person, by virtue of language, constructs social meaning.

The defence of the centrality of language in emotional construction can be difficult to understand if we do not depart from a molecular view of language. In the complexity of human conversations, language is much more than the constructions of words. We believe that emotions acquire their meanings by being situated in a narrative plot. As stated elsewhere, we are able to construct meaning out of the diversity of any experience by imposing some kind of pattern or order on this experience (Gonçalves et al. 2000). In human beings, emotions are rendered meaningful by locating them in a narrative order. As Gergen has noted, 'To achieve intelligibility the emotional performances must be recognizable components of an ongoing chain of action' (1994: 223). Similarly, Greenberg and Paivio (1997) recognized that at least certain complex emotions such as jealousy require a narrative to be understood. However, the vast majority of human emotional experience consists of the so-called complex emotions. This being so, we would venture a step further, by assuming that all construction of emotional meaning is co-dependent on a narrative order.

We believe that the inspection of narratives will bring some light on how different psychological disorders can be differentiated in terms of emotions, how these emotional narratives are developed and how they change in psychotherapy. In what follows, we discuss each one of these aspects, illustrating with data from different research projects. 


\section{Emotional narratives and psychopathology}

We have argued elsewhere (Gonçalves et al. in press) that psychopathology can be understood in terms of lack of emotional narrative flexibility. That is, patients diagnosed with certain disorders will construct narratives limited to certain number of typical emotions. In order to illustrate this, we will now present some data from a research programme conducted in our laboratory with the objective of identifying prototype narratives from individuals with different psychological dysfunctions. In this research programme we interviewed 24 agoraphobic, 18 drug-dependent, 20 alcoholic, 11 anorexic and 20 depressive patients. Significant life narratives were collected from each subject and analysed by the qualitative methodologies of grounded analysis (cf. Rennie et al. 1988).

Following the diagnostic procedure, subjects went through a structured interview where they were guided in a process of image-based recall of several life narratives. The subjects were asked to select one among the narratives recalled for further exploration. In the second part of the interview, each subject responded to a set of questions regarding the narrative, in order to obtain details of both the external and internal components of the experience selected. All narratives were taped and subsequently transcribed.

Transcripts of the interviews were categorized into the seven different dimensions suggested by narrative grammar structure: setting, initiating event, internal response, goal, actions, outcome, and ending. The content of the narratives within each dimension of the grammar-structure categories was further analysed in order to allow the identification of different meaning categories. These meaning categories were further collapsed into clusters of hierarchical meanings.

Using the clusters of hierarchical meaning, a prototype narrative for each psychopathological sample was constructed. Finally, psychopathological groups were matched with a equal number of control subjects and all were shown the prototype narrative and asked to rate, on a five-point Likert scale, the degree to which that narrative could be understood as something plausible as a personal life event (cf. Gonçalves and Machado 1999).

One of the most interesting findings came from the fact that different prototype narratives were organized around specific emotional themes and that these emotional themes clearly discriminated narratives from the differently diagnosed groups in our sample. We shall now briefly summarize the prototype narratives for each group.

The prototype narrative for the drug-dependent sample can be stated as an episode taking place in a public setting and activated by some uncontrolled situation. Individuals are guided in this situation by the objective of avoiding some painful situation and seeking pleasure. Their actions are 


\section{4 Óscar F. Gonçalves and Paulo P. P. Machado}

typically non-confrontative and externally controlled, with a compound of internal states oscillating between the dialectics of pain/suffering and pleasure/relief. The outcome of the narrative is typically the maintenance of the status quo, with the subjects ending up with a sense of social loss and loss of personal power.

For the alcoholic sample, the prototype narrative can be summarized as an episode taking place in an intimate context and activated by an experience of loss. Individuals are guided in this situation by the objective of overcoming and escaping the situation. Their actions are of crying and escaping with accompanying feelings of sadness and tension. The outcome of the narrative is typically the feeling of isolation, with the subjects ending up with a sense that this situation was the beginning of a personal collapse.

The prototype narrative of the anorexic patients is typically an episode that has as its central scenario the school and the house. It is a situation where they are confronted and disappointed by the attitude of significant others. Subjects try to assert themselves in this confrontation by opposing and crying while experiencing sadness, anxiety, disappointment and anger. The typical outcome is the failure of the subject to assert his/her own wishes, ending up disappointed with the new face of life that they come to realize is still difficult to accept.

For the agoraphobic subjects, the prototype narrative takes place between hospital and home and is activated by a situation that is seen as both a separation and a risky challenge. The subjects try to maintain security and overcome this challenge by a mixture of avoidance, crying and searching for help, while at the same time challenging themselves. They experience in this process a compound of different feelings such as fear, insecurity, loss of control, abandonment, sadness, despair, offence, revenge and personal affirmation. Individuals try to reassume a sense of calm and tranquillity by avoidance, crying, challenging themselves and searching for help. The situation typically ends with a dichotomous experience: on one side, an increased awareness of the dangers and, on the other side, the sense of self-competence and efficacy.

Finally, for the depressive subjects the narrative takes place at home and is activated by a personal loss or disappointment. The person strives to understand and accept the situation while, simultaneously, experiencing feelings of sadness, anger and incredulity. The person typically freezes and alienates from others. The situation ends with a sense of helplessness, abandonment and vulnerability.

As can easily be seen, all the narratives have emotions as central themes of the episode. Additionally, the different prototype narratives are clearly distinguishable in terms of these emotions and the way these emotions are embedded into distinct narrative plots. 
In order to see in which way the patients with the different diagnoses would identify with the different emotional narratives, we proceeded to the computation of the convergent validity of the prototype narratives by testing the verisimilitude of each prototype narrative for a sample of the dysfunctional samples for each clinical diagnosis and the control groups. All subjects were confronted with the prototype narrative and asked to rate on a five-point Likert scale the degree to which that narrative could be understood as something plausible as a personal life event.

The results show that the clinically diagnosed samples evaluate the prototype narrative as significantly more related with their personal lives than the control sample (drug dependants $-\chi^{2}=35.9 ; \mathrm{p}<.0001$; alcoholics $-\chi^{2}=40.3 ; \mathrm{p}<.0001 ;$ anorexics $-\chi^{2}=24.67 ; \mathrm{p}<.0001$; agoraphobics $\chi^{2}=41.0 ; \mathrm{p}<.0001 ;$ depressives $\left.-\chi^{2}=60.67 ; \mathrm{p}<.001\right)$.

Summing up, the data suggest that persons diagnosed with different pathologies can be differentiated in terms of invariant emotional narratives. This raises the question of how these emotional narrative prototypes are developed in the first place. It is to this question that we shall turn next.

\section{The development of emotional narratives}

We believe that emotional narratives are the products of socialization processes in given 'emotional narrative communities'. That is, in the course of their development individuals acquire specific ways of talking about their experience by engaging in conversation and story-telling practices from their social and cultural communities.

Research has been showing that parents have certain conversational and narrative practices that may model children's subsequent ways of emotional construction. In a meta-analysis of studies on how parents' talk to their children is moderated by gender, Leaper et al. (1998) came up with some interesting conclusions. Basically, they found that mothers tend to use with their children a more emotional discourse, as expressed by supportive (i.e. positive response language, such as praise, approval, agreement, acknowledgement or collaboration) or negative speech (criticism, disapproval or disagreement), while fathers tend to privilege in their talking interaction with children more cognitive discourse, as expressed by directive (i.e., imperative statements or direct suggestions) or informing speech (i.e., descriptive statements, opinions or explanations). These data suggest that different gender communities tend to construct differential emotional conversations, the mothers being those who are more responsible for the socializing of emotional language.

A recent research study has carried this conclusion a step further. Chance and Fiese (1999) looked at the way mothers and fathers construct their stories and share them with their male and female pre-school children. One 


\section{6 Óscar F. Gonçalves and Paulo P. P. Machado}

hundred and twenty-five, mainly Caucasian (92 per cent) families of 56 boys and 65 girls participated in this study. Male and female parents were instructed to tell their sons or daughters a story 'about when you were growing up and were disappointed about something'. The order for fathers and mothers telling was alternated randomly across the sample. The stories were videotaped, transcribed and analysed according to the emotional content in one of the four mutually exclusive categories: angry, sad, mixed, or unelaborated/no emotional frame. One female and one male assistant coded the transcripts, with a satisfactory level of agreement $(k=.68)$. Results show that mothers told stories more charged with sadness, while fathers more frequently told stories without emotional frame $\left(\chi^{2}=4.89 ; \mathrm{p}<.027\right)$. Additionally, significant differences were found in the way parents construct their emotional narratives as told to their boys vs. their girls, the mothers constructing significantly more sad narratives for their daughters than for their sons $\left(\chi^{2}=6.91 ; \mathrm{p}<.009\right)$.

These results are interesting enough to suggest that the narratives mothers construct for their children convey some of the core emotions, and that at a very early stage some of the gender-related, socially constructed stereotypes about emotionality are already operating. Even though we do not know of any research linking early narrative practices with the onset of emotional narrative themes in psychopathology, it is not difficult to assume that narrative practices that are characterized by inflexible emotional narratives would have a strong impact on the emotions constructed later on in adulthood.

Now, there remains a third question to be discussed - can psychotherapy introduce change in emotional narratives?

\section{The changing of emotional narratives}

Finally, we may assume that therapeutic change corresponds to an increase of diversity and complexity in emotional narratives. A curious study in our laboratory illustrates how the increase of change in emotional narratives correlates with therapeutic change.

Twenty-one patients diagnosed with AIDS participated in this study. Within one week after being diagnosed the patients were asked, on five consecutive days, to write spontaneously about the experience of being diagnosed. The narrative task followed the typical protocol developed by James Pennebaker:

For the next five days, I would like for you to write about your very deepest thoughts and feelings about the traumatic experience of being diagnosed with AIDS. In your writing, I'd like you to really let go and explore your very deepest emotions and thoughts. You might tie your 
topic to your relationship with others, including parents, lovers, friends, or relatives, to your past, your present, or your future, or to who you have been, who you would like to be, or who you are now. Don't be concerned about spelling, grammar or sentence structure, the only rule is that once you begin writing, continue to do so without stopping. (adapted from Pennebaker and Seagel 1999: 1244)

Several measures of psychological health were taken before and three months after the narrative assignment (e.g. Beck Depression Inventory, Brief Symptom Inventory, and Beck Hopelessness Scale). The participants' narratives were analysed using the narrative process coding system (Angus et al. 1996) in order to evaluate the predominance of one of the three narrative modes: external, internal and reflexive. Finally, an adaptation of the Linguistic Inquiry and Word Count (LIWC) programme developed by Pennebaker and Francis (1996) was used in order to analyse the type of emotional words present in the patients' narratives.

Based on the results of the psychological health measures, a K-means cluster analysis was performed in order to contrast two groups of patients those identified as most disturbed and those identified as least disturbed. The narratives of the first two days versus the narratives of the last two days of writing were analysed and compared between groups.

Concerning the narrative modes, a curious pattern was found. The most disturbed group had an increase in external mode across the five days of writing (39.5 per cent in the first two days vs. 51 per cent in the last two) and a decrease in reflexive mode (42 per cent in the first two days vs. 29.5 per cent in the last two). By contrast, the least disturbed group increased in the internal mode ( 7.5 per cent in the first two days vs. 14 per cent in the last two) and a decrease in the reflexive mode (53 per cent in the first two days vs. 45 per cent in the last two). In sum, what seems to be differentiating the two groups is the increase of the external mode in the most disturbed group and the increase of the internal mode in the least disturbed group. When we look more closely at the emotional words used, we see a tendency by the least disturbed group to decrease the number of negative emotional words ( 44.5 per cent in the first two days vs. 33.5 per cent in the last two) as contrasted with the tendency of the most disturbed patients to increase the number of negative emotional words used (44.5 per cent in the first two days vs. 48 per cent in the last two). These data are convergent with most of the results found by Pennebaker (1997), suggesting that there are significant changes in the emotional nature of the narratives that may be good predictors of psychological health, namely the increase of emotional discourse in the direction of more positive emotional words. We believe, however, that separating emotions into positive and negative is a crude oversimplification of the richness of emotional narratives. Future 
studies need to inspect more closely the level of differentiation of the internal or emotional modes (i.e. variety of emotional words, combination of emotions, simple vs. complex emotions, etc.).

\title{
Conclusion
}

In this paper we have defended the idea that emotions are central to the evaluation and understanding of change processes in psychotherapy. However, in order to understand their role in psychotherapy fully, we need to move beyond biological reductionism and acknowledge the complex nature of emotions. In human beings the acknowledgement of this complexity implies the recognition that emotions, even though biologically rooted (like everything in life), are above all a socially constructed phenomenon. This social construction operates via language, which acquires both personal and social meaning in a narrative plot.

We have defended the idea that these narratives may be an essential process to understand psychological disorders, as well as how these disorders are developed and can be changed in psychotherapy.

Research reviewed in this paper suggests that:

1 different types of psychological disorders may be differentiated in terms of emotional narrative prototypes;

2 emotional narratives seem to grow out of given conversational communities where certain ways of emotional telling are dominant;

3 finally, therapeutic change seems to correlate with an increase in emotional narrative modes as well as the type of emotions being constructed.

\author{
correspondence to Óscar F. Gonçalves \\ Departamento de Psicologia \\ Universidade do Minho \\ 4700 Braga, Portugal \\ E-mail: goncalves@iep.uminho.pt
}

\section{References}

Angus, L., Hardtke, K. and Levitt, H. (1996) The Narrative Process Coding System Manual: Expanded Edition, Department of Psychology, York University, North York, Ontario, Canada.

Averill, J. (1996) 'An analysis of psychophysiological symbolism and its influence on theories of emotion', in R. Harré and W.G. Parrot (eds) The Emotions: Social, Cultural and Biological Dimensions, London: Sage, pp. 204-28.

Campbell, L., Anderson, K.J. and Sanders, P. (1998) 'Moderators of gender 
effects on parents' talk to their children: a meta-analysis', Developmental Psychology, 34: 3-27.

Chance, C. and Fiese, B.H. (1999) 'Gender-stereotyped lessons about emotion in family narratives', Narrative Inquiry, 9: 243-56.

Damásio, A. (2000) The Feeling of What Happens, London: Heinemann.

Gergen, K.J. (1994) Realities and Relationships, Cambridge, MA: Harvard University Press.

Gonçalves, O.F. and Machado, P.P.P. (1999) 'Cognitive narrative psychotherapy: research foundations', Journal of Clinical Psychology, 55: 1179-91.

Gonçalves, O.F., Korman, Y. and Angus, L. (2000) 'Constructing psychopathology from a cognitive narrative perspective', in R.A. Neimeyer and J.D. Raskin (eds) Constructions of Disorder, Washington, DC: APA Press, pp. 265-84.

Gonçalves, O.F., Machado, P.P., Korman, Y. and Angus, L. (in press) 'Assessing psychopathology: a narrative approach', in L. Beutler (ed.) Alternatives to DSM-IV, Washington, DC: APA Press.

Greenberg, L.S. and Paivio, S.C. (1997). Working with Emotions in Psychotherapy, New York: Guilford Press.

Greenberg, L.S. and Safran, J.D. (1987) Emotion in Psychotherapy, New York: Guilford Press.

Greenberg, L.S. and Safran, J.D. (1989) 'Emotion in psychotherapy', American Psychologist, 44: 19-29.

Hill, C.E. and O'Grady, K.E. (1985) 'A list of therapist intentions: illustrated in a single case and with therapists of varying theoretical orientations', Journal of Counseling Psychology, 32: 3-22.

Lazarus, R. (1982) 'Thoughts on the relations between emotion and cognition', American Psychologist, 37: 1019-24.

Lazarus, R. (1984) 'On the primacy of cognition', American Psychologist, 39: 124-9.

Leaper, C., Anderson, K.J. and Senders, P. (1998) Moderators of gender effects on parents' talk to their children: a meta-analysis, Developmental Psychology, 34: $3-27$.

Lupton, D. (1998) The Emotional Self, London: Sage.

Mahoney, M.J. (1991) Human Change Processes, New York: Basic Books.

Mahoney, M.J., Norcross, J.C., Prochaska, J.O. and Missar, C.D. (1989) 'Psychological development and optimal psychotherapy: converging perspectives among clinical psychologists', Journal of Integrative and Eclectic Psychotherapy, 8: 251-63.

Orlinsky, D.E. and Howard, K.I. (1986) 'Process and outcome in psychotherapy', in S.L. Garfield and A.E. Bergin (eds) Handbook of Psychotherapy and Behavior Change, New York: Wiley.

Pennebaker, J.W. (1997) Writing about emotional experiences as a therapeutic process, Psychological Science, 8: 3-27.

Pennebaker, J.W. and Francis, M.E. (1996) 'Cognitive, emotional, and language processes in disclosure', Cognition $\mathcal{E}$ Emotion, 10: 601-26.

Pennebaker, J.W. and Seagel, J. (1999) 'Forming a story: the health benefits of narrative', Journal of Clinical Psychology, 55: 1243-54. 
Rennie, D.L., Philips, J.R. and Quartaro, G.K. (1988. 'Grounded theory: a promising approach to conceptualization in psychology?', Canadian Psychology, 29: 139-50.

Weimer, W.B. (1977) 'A conceptual framework for cognitive psychology: motor theories of the mind', in R. Shaw and J. Bransford (eds) Perceiving, Acting, and Knowing, Hillsdale, NJ: Erlbaum, pp. 267-311.

Williams, J.M., Watts, F.N., Macleod, C. and Mathews, A. (1997) Cognitive Psychology and Emotional Disorders, 2nd edn, Chichester: Wiley.

Zajonc, R.B. (1980) 'Feeling and thinking: preferences need no inferences', American Psychologist, 35: 151-75.

Zajonc, R.B. (1984) 'On the primacy of affect', American Psychologist, 39: 117-23. 